\title{
Venous malformation and Sodium tetra decyl sulphate as sclerosant: a treatment option
}

\section{Dr. Assif Iqbal Shaikh}

\section{Dr. Imran Ahmad*}

\section{Dr. M. Fahud} Khurram

\section{Dr. Lalit Agrawal}

(M.S. Gen. Surgery) Resident MCh Plastic surgery, Department of plastic surgery, Jawaharlal Nehru medical college and hospital, Aligarh (UP), India.

(Mch. Plastic surgery)Professor Department of plastic surgery,Jawaharlal Nehru medical college and hospital, Aligarh (UP), India. ${ }^{*}$ Corresponding Author

(Mch. Plastic surgery), Associate Professor,Department of plastic surgery, Jawaharlal Nehru medical college and hospital, Aligarh (UP), India.

(DNB Gen. Surgery),Resident MCh Plastic surgery, Department of plastic surgery, Jawaharlal Nehru medical college and hospital, Aligarh (UP), India.

ABSTRACT Venous malformations are common vascular lesion with variable presentation. They are benign but sometimes troublesome because of their location, size, bleeding. There are various treatment modalities available and different patients are benefitted with different modality. Sclerotherapy is good nonsurgical means of treatment. This study is undertaken to further explore the utility of sodium tetra decyl sulphate as a sclerosant for venous malformation.

KEYWORDS : venous malformation, sclerotherapy, Sodium tetradecyl sulphate

Introduction - Congenital vascular malformations are well known pathology of blood vessels including artery, vein, and capillaries. Venous malformation (VM) are low-flow vascular malformations [1]. Venous malformation that are apparent at infancy or at birth are worrisome and cause of anxiety in parents. Spontaneous involution is very rare in venous malformation and they increase in size with the growth of child [2].

There is no standard treatment protocol for the management of VM. Treatment options of low flow VM include observation, sclerotherapy or embolization [3,4], LASER ablation [5], cryotherapy [6], or surgical resection.

Material and method: This study was done in Jawaharlal Nehru medical college and hospital from December 2015 to December 2018. Study includes 25 patients of all age group and both genders. Lesions of any size and location was included into study. Swelling was most common presenting complaint followed by bleeding, ulceration, pain, aesthetic appearance and functional difficulties. A color doppler study was done to confirm the lesion. Size, site, texture and color of lesion was noted before starting sclerotherapy. The doses of sclerosing agent was calculated by size of lesion $(0.1 \mathrm{ml} / \mathrm{cm} 2)$ in follow up of every 3 weeks.

0.1 to $2 \mathrm{ml}$ of injection sodium tetradecyl sulphate was given by Insulin syringe depending upon size of lesion on 3 weekly intervals after taking informed consent about procedure, its complications and outcome. Injection was performed intralesional (intravascular and extravascular compartment). Lesion was compressed post injection to keep drug into the lesion for 30 minutes. Injection dexamethasone was also given intramuscularly before sclerotherapy according to age and weight to prevent any hypersensitivity reaction beforehand.

All patients were monitored after injection for 24 hours indoor and outdoor basis depending upon severity of lesion and any anticipation of complication. Antibiotics, analgesics, antiinflammatory agents were given. Number of injections, complication and outcome were recorded. Therapy was stopped when lesion disappears or stopped reducing further in size.
Results:

Table 1: Gender distribution

\begin{tabular}{|c|c|}
\hline Male & 10 \\
\hline Female & 15 \\
\hline
\end{tabular}

Table 2: Age distribution

\begin{tabular}{|c|c|}
\hline$<14$ years & 20 \\
\hline$>14$ years & 5 \\
\hline
\end{tabular}

Table 3: Location distribution

\begin{tabular}{|c|c|}
\hline Lips and buccal mucosa & 7 \\
\hline Cheek & 6 \\
\hline Forehead & 4 \\
\hline Neck & 3 \\
\hline Extremities & 5 \\
\hline
\end{tabular}

Lesions treated had area range from $1-10 \mathrm{~cm} 2$. All patients were followed up for 6-36 months. 18 patients had complete or near complete response in the form of disappearance of lesion along with symptomatic improvement. 7 patients had incomplete response in the form of less reduction in size, in 6 months of follow up and, were repeated for therapy till complete resolution, however symptomatic improvement was there. Most of the lesions were improved with 4 sessions of injection, however few patients improved after 6 sessions and none were after that. Most common complication were pain and swelling. One patient had superficial skin necrosis and bleeding that was healed with conservative management.

Long term complication or sequelae was hyper or hypopigm entation and scar formation occurs in 3 patients.

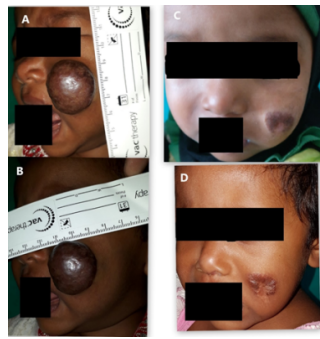

Pic. 1: A\&B demonstrating vertical and horizontal dimension of lesion and C\&D demonstrating results after $5^{\text {th }}$ and $6^{\text {th }}$ session of lesion respectively. 
Discussion: Hemangioma term was classified into two (i.e., hemangioma and vascular malformation) by Mulliken and Glowacki in 1982 [7]. Vascular malformations are of two types (i.e., low and high flow) due to hemodynamic status [8]. Vascular malformations are not uncommon disorders. Patients usually seek consultation for swelling, bleeding, pain, infection, functional difficulty and cosmesis. Venous malformations are most common vascular malformation and most commonly located on head and neck [9].

Surgery is the best treatment plan offered if possible but, it is not always possible due to chances of incomplete excision, bleeding, recurrence, location and, because of cosmetic concern. These obstacles lead to exploration of other treatment modalities like sclerotherapy, LASER, cryotherapy, radiotherapy and, cautery [10].

Percutaneous sclerotherapy with or without surgical resection is a wide spread practical treatment modality nowadays. Sclerosant agents are mainly contact irritants and usually classified as detergents, osmotic agents and chemical irritants. Detergent acts by changing the surface tension of cells and example includes polidocanol, sodium tetradecyl sulfate, sodium morrhuate and ethanolamine oleate, Osmotic agents acts by dehydration of cells which ultimately leads to cell damage and these includes Hypertonic saline, hypertonic saline / dextrose. Chemical irritants have corrosiveness and includes Chromated glycerin, polyiodinated iodide [11,12]. Sodium tetradecyl sulfate has been used for long time in the treatment of varicose vein, hemorrhoids and hemangioma [13]. Intralesional injection causes intimal lining inflammation and thrombus formation. This usually occludes the injected vein and subsequent formation of fibrous tissue results in partial or complete vein obliteration that may or may not be permanent. Injection of sodium tetradecyl sulphate is painless and associated with less allergic reaction and as there is minimal or no hemolysis so, chances of hyperpigmentation are less [14].

Saraf S. reported male to female ratio 1:2, involvement of head and neck in 17 patients, trunk in 3, upper limbs in 13 and lower limbs in 7 patients out of 40 patients studied. The lip was found to be involved in nine out of 17 cases of head and neck presentation [15]. In present study male to female ratio was 1:1.5 with $80 \%$ of lesion located at head and neck and $20 \%$ over extremities. This discrepancy may be due to small number of our study and exclusion of areas requiring surgical excision.

In our study main complaint was swelling in all cases and, most are concerned about cosmesis. Atul Shishodia et al. reported swelling as main complaint in all case and pain in $12 \%$, bleeding in $8 \%$, ulceration in $4 \%$ cases as presenting complaints [16].

Bajpai $\mathrm{H}$ et al. studied size of lesion ranged from $0.48 \mathrm{~cm} 2$ to 5 $\mathrm{cm} 2$ in size [17]. In Alakailly $\mathrm{X}$ et al. study they reported 1 to 8 $\mathrm{cm} 2$ lesions [18]. In present study size of lesion ranged from 1$10 \mathrm{~cm}^{2}$. We have measured maximum length and width for calculation of area however these lesions are never flat and third dimension is missing and so actual area can't be exactly comment upon. Actual method of calculation was not mentioned in literature.

We had complete or near complete resolution is seen in 18 patients $(72 \%)$ and incomplete response seen in $28 \%$ patients. Siniluoto TM reported late results of $34 / 38$ patients who responded to the follow-up questionnaire, excellent or good in 23 patients $(68 \%)$, moderate in eight, unchanged in three, and were worse in one [3].

We found that most of the lesions were improved with 4 sessions of injection, however few patients improved after 6 sessions and none were after that. P. Stimpson et al. reported overall average of 3 treatments (range 1-9). In 4 patients a single treatment was sufficient. For those patients requiring more than one injection, a mean of 4 treatments were required over an average period of 28 months. Larger volume lesions appear to require more treatments than low volume lesions [19].

In present study most common complication was pain and swelling after injection. One patient had skin ulceration and bleeding that was managed conservatively. Long term sequalae noted was hyper or hypopigmentation and scar formation in 3 patients. Khandpur S. et al. noted inflammation blister formation and crusting in $53.8 \%$ patients and atrophic scarring in $30.7 \%$ patients [20]. In the O'Donovan and colleagues' study, skin ulceration developed in $14.3 \%$ cases after sclerotherapy [21]

As this is an invasive procedure and we are using agent which act by causing destruction and fibrosis of vessel wall, so these complications are expected and with proper technique these complications can be minimized as already demonstrated by different studies.

Other treatment modalities like LASER, cryotherapy can be used with variable outcome but are not available easily and are costly for people of low socioeconomic groups. Surgical excision is invasive and may cause local deformity which may be cosmetically unacceptable.

So, to conclude sclerotherapy by injection sodium tetra decyl sulphate is cheap, easily available, convenient OPD procedure which gives acceptable results in appropriately selected patient by skilled physician.

\section{REFERENCES}

1. Ethunandan M, Mellor TK (2006) Haemangiomas and vascular malformations of the maxillofacial region-a review. Br J Oral Maxillofac Surg Aug 44(4):263-272

2. D.J. Choi, A.I. Alomari, G. Chaudry, D.B. Orbach Neurointerventional management of low-flow vascular malformations of the head and neck, Neuroimaging Clin. N. Am. 19 (2009) 199-218.

3. Siniluoto TM, Svendsen PA, Wikholm GM, Fogdestam I, Edstrom S. Percutaneous sclerotherapy of venous malformations of the head and neck using sodium tetradecyl sulphate (sotradecol) Scand J Plast Reconstr Surg Hand Surg. 1997:31(2):145-150. doi: 10.3109/02844319709085481. [PubMed] [CrossRef] [Google Scholar]

4. Lee CH, Chen SG. Direct percutaneous ethanol instillation for treatment of venous malformation in the face and neck. Br J Plast Surg. 2005; 58(8): 1073-1078. doi: 10.1016/j.bjps.2005.04.014

5. Scherer K, Waner M. Nd:yAG lasers $(1,064 \mathrm{~nm})$ in the treatment of venous malformations of the face and neck: challenges and benefits. Lasers Med Sci. 2007;22(2):119-126. doi: 10.1007/s10103-007-0443-0.

6. Cornelis F, Neuville A, Labreze C, Kind M, Bui B, Midy D et al (2012) Percutaneous cryotherapy of vascular malformation: initial experience. Cardiovasc Interv Radiol

7. Mulliken JB, Glowacki J (1982) Hemangiomas and vascular malformations in infants and children: a classification based on endothelial characteristics. Plast Reconstr Surg Mar 69(3):412-422

8. Johann AC, Aguiar MC, do Carmo MA, Gomez RS, Castro WH, Mesquita RA (2005) Sclerotherapy of benign oral vascular lesion with ethanolamine oleate: an open clinical trial with 30 lesions. Oral Surg Oral Med Oral Pathol Oral Radiol Endod Nov 100(5):579-584

9. Berenguer B, Burrows PE, Zurakowski D, Mulliken JB. Sclerotherapy of craniofacial venous malformations

10. complications and results. Plast Reconstr Surg 1999;104:1-15

11. Govrin-Yehudain J, Moscona AR, Calderon N, Hirshowitz B (1987) Treatment of hemangioma by sclerosing agents: an experimental and clinical study. Ann Plast Surg 18:465-469

12. Ochsner A, Garside E. The intravenous injection of sclerosing substances Experimental comparative studies of changes in the vessels. Ann Sug 1932;96:691-718.

13. Rotter SM, Weiss RA. Human saphenous vein in vitro model for studying the action of sclerosing solutions. J Dermatol Surg Oncol 1993; 19:59-62.

14. Minkow B, Laufer D, Gutman D (1979) Treatment of oral hemangioma with local sclerosing agents. Int J Oral Surg 8:18-21 Indian J Otolaryngol Head Neck Surg (July-September 2012) 64(3):205-207 207123

15. Dietzek CL. Sclerotherapy: Introduction to solutions and techniques. Perspect Vasc Surg Endovasc Ther 2007; 19:317-24.

16. Saraf S. Role of sodium tetradecyl sulfate in venous malformations. Indian J Dermatol 2006;51:258-61

17. SHISHODIA,A.SHARAN J.PANDEY.C.P.SHARMA,B.S., (2018).Therapeutic use of Sodium Tetradecyl Sulphate in Management of Cutaneous Vascular 
Malformations, 7(3), SO01-SO05. https:// www. doi. org/10. 7860/ JCDR/ 2018/ $35996 / 2403$

18. Bajpai H, Bajpai S. Comparative analysis of intralesional sclerotherapy with sodium tetradecyl sulfate versus bleomycin in the management of low flow craniofacial soft tissue vascular lesions. J Maxillofac Oral Surg. 2012;11(1):13-20.

19. Alakailly X, Kummoona R, Quereshy FA, Baur DA, González AE. The use of sodium tetradecylsulphate for the treatment of venous malformations of the head and neck. J Maxillofac Oral Surg. 2015;14(2):332-38.

20. Stimpson P, Hewitt R, Barnalle A, Roebuck DJ, Hartley B (2012) Sodium tetradecyl sulfate sclerotherapy for treating venous malformations of the oral and pharygeal regions in children. Int J Pediatr Otorhinolaryngol 76 (4): 569-573

21. Khandpur S, Sharma VK. Utility of intralesionalsclerotherapy with $3 \%$ sodiumtetradecyl sulphate in cutaneous vascular malformations. Dermatol Surg. 2010;36:340-46.

22. O'Donovan JC, Donaldson JS, Morello FP, et al. Symptomatic hemangiomas and venous malformations in infants, children, and young adults: treatment with percutaneous injection of sodium tetradecyl sulfate. Am J Roentgenol 1997;169:723-9. 